\title{
Prevalence of Opioid Side Effects in Patients with Protocolized Analgesia for the Management of Acute Postoperative Pain
}

\author{
F Leticia Hernández ${ }^{1 *}$, María Guadalupe Escalona Hernández ${ }^{2}$, Alfredo Ramírez Bermejo ${ }^{3}$ and Antonio Castellanos \\ Olivares $^{4}$ \\ 'Medical specialist in pain medicine, Coordinator of the Acute Pain service at "Specialty Hospital National Medical Center XXI Century, Social Security", \\ México
}

2Medical Specialist in pain medicine at the "Specialty Hospital National Medical Center XXI Century, Social Security", México

${ }^{3}$ Medical Specialist in pain medicine at "Hospital General of Mexico O.D, México

${ }^{4}$ Chief of Anesthesiology Service "Specialty Hospital National Medical Center XXI Century, Social Security", México

Submission: November 16, 2019; Published: December 03, 2019

*Corresponding author: F. Leticia Hernández Hernández, Medical specialist in pain medicine, Coordinator of the Acute Pain service at "Specialty Hospital National Medical Center XXI Century, Social Security", Av. Cuauhtémoc 330, Colonia Doctores, México

Abstract

Acute Postoperative Pain is the main model of acute pain that results from nociceptive stimulation, the result of direct and indirect aggression of a surgical act. $70 \%$ of postsurgical patients suffer moderate pain, and $30 \%$ severe. Opioids are indicated to manage moderate to severe pain, their use triggers gastrointestinal, respiratory, urinary among other side effects. The WHO considers a side effect or adverse reaction of a drug to the expected and harmful reactions of pharmacological agents.

Objective: To know the prevalence of opioid side effects in postoperative patients who received protocolized analgesia.

Material and methods: Descriptive, observational, cross-sectional, retrospective study of patients who received protocolized analgesia with opioids from March - September 2018, at the "Specialty Hospital National Medical Center XXI Century". The study variables were demographic data, side effects (nausea, vomiting, constipation, pruritus, sedation, etc.). For the analysis of results, the SPSS version 22 program was used.

Results: 320 records of patients who received opioid analgesia were included. The prevalence of side effects was $47 \%$ ( 140 patients). The opioids that are related to side effects were: intravenous morphine (nausea $17.8 \%$, vomiting $16.4 \%$ ), intravenous buprenorphine (sedation $7.1 \%)$, no case of respiratory depression.

Conclusions: The prevalence of side effects in patients who received opioids for Acute Postoperative Pain was lower than that reported in other studies, possibly the anticipated use of antiemetics, and decreased analgesic doses of opioids.

Keywords: Postoperative pain; Protocolized analgesia; Opioid; Side effects

Abbreviations: DAP: Acute Postoperative Pain; PCA: Patient Controlled Analgesia; IM: Intramuscular; WHO: World Health Organization; 95\% CI: 95\% Confidence Interval; OR: Odds Ratio; ASA: American Society Of Anesthesiologists

\section{Introduction}

Acute Postoperative Pain, is the main model of acute pain and is produced by nociceptive stimulation that results from direct and indirect aggression of the surgical act [1]. The direct aspects are due to the direct injury caused by the incision that affects the nerve endings of the different structures as well as the manipulation. Indirect aggression is a consequence of the surgical act such as bladder, intestinal distension, muscle spasms, nerve injury due to improper traction, anesthetic technique, the patient's baseline pathology. Direct and indirect aggression results in the release of algogenic chemical substances in the immediate environment of nociceptors, the main substances are ions $\left(\mathrm{H}^{+}, \mathrm{K}^{+}\right)$; neurotransmitters such as serotonin, norepinephrine, chemical mediators such as bradykinins, prostaglandins, cytokines; and vasoactive peptides such as substance $P$, with the generation of nociceptive stimuli that reach segmental, supra-segmental and cortical nerve centers [2]. These responses define the reaction of the organism against aggression and constitute the basis that explains the post-surgical aspects related to pain. It is estimated 
that of all postoperated patients, $70 \%$ have moderate pain and $30 \%$ severe, and for the management of moderate to severe pain in postoperated patients, opioids are recommended, which are related to the presence of side effects. The WHO defines a side effect or adverse reaction of a drug, to the expected, harmful reactions. While the association of pharmacovigilance places them as the response to a drug that is harmful, unintended, produced at recommended doses for prophylaxis, diagnosis and / or treatment [3]. The side effects of opioids have been estimated in approximately in $80 \%$, mainly affecting the gastrointestinal tract in $30 \%$ and a smaller proportion to the rest of the devices and systems. Some reports be consider that buprenorphine triggers side effects up to $52 \%$ at the gastrointestinal level. Oxycodone produces constipation in $95 \%$, followed by morphine. The main drugs related to the presence of nausea, in decreasing order are: Buprenorphine, morphine, fentanyl and tramadol. The appearance of vomiting and dizziness are considered dose-dependent and tramadol is the main representative in percentage form. At the level of the central nervous system, the main side effects are sedation, drowsiness, and are associated with morphine between $8-90 \%$, the presence of headache reaches $10 \%$ [4]. The most serious side effect of opioids is respiratory depression and is due to the inhibition of the respiratory activity of the brainstem, and probably due to effects on cortical areas that mediate breathing, but of those less known [5]. Respiratory depression is a side effect of opioids that appears slowly and gradually, Martínez and collaborators in a retrospective study that included 189 patients reported the prevalence of $71.4 \%$ but this was in palliative patients [6า-8].

In a multicenter study that included 26 hospitals in the United States in which 37,031 subjects participated, of which 99\% opioids were received for the control of Acute Postoperative Pain, reported that only $19 \%$ had side effects, and the opioid with which the side effects were most related was morphine in $29 \%$. They evaluated 3 techniques of postoperative analgesia (im, PCA epidural analgesia) for major surgery for the period of 1988-1999, respiratory depression was reported below $1 \%$, and hypotension in 5\% [9]. A study involving 800 authentic MEDLINE publications related to the treatment of Acute Postoperative Pain using 3 analgesic techniques (intramuscular, PCA, epidural analgesia) and of which 532 were selected for analysis, 183 corresponded to nausea and vomiting, 89 to sedation, 166 to pruritus, 94 to urinary retention and representing more than 100,000 patients; and from which they threw the following information:

Side effects related to the 3 analgesic techniques:

Overall mean incidence of nausea $=25.2 \%, 95 \%$ CI; $19.3-32.1$

Overall mean incidence of vomiting $=20.2 \%, 95 \% \mathrm{CI} ; 17.5$ 23.2

They found that patient-controlled analgesia was associated with the highest incidence of nausea, while vomiting was not affected by the analgesic technique.
Regarding sedation they found a wide variation of the criteria, and the result was: Overall mean incidence of mild sedation = 23.9\%, 95\% CI; 23 - 24.8

Overall mean incidence of excessive sedation $=2.6 \%, 95 \% \mathrm{CI}$; $2.3-2.8$

Epidural analgesia was significantly lower for sedation.

Overall average incidence of pruritus $=14.7 \%, 95 \% \mathrm{CI} ; 11.9$ $-18.1$

The im technique showed the lowest percentage.

Overall mean incidence of urinary retention $=23 \%, 95 \% \mathrm{CI}$ $17.3-29.9$

The epidural analgesic technique was the one that caused more urinary retention

From these results, the authors make recommendations for standards for the presence of side effects related to the management of Acute Postoperative Pain in patients undergoing major surgery, this are: Nausea 25\%, Vomiting 20\%, Mild Sedation $24 \%$, Excessive Sedation 2.6\%, Pruritus 14.7\%, Urinary Retention managed with bladder catheterization $23 \%$. An important aspect of this recommendation was that for acute pain services these side effects should be of lower incidence [10].

In a study involving 60 women undergoing caesarean section, randomly distributed and 20 patients per group, compared the side effects of analgesia for the management of Acute Postoperative Pain using morphine with 3 techniques (im, PCA, epidural). The results of side effects according to the technique were: Nausea: $\mathrm{im}=25 \%, \mathrm{PCA}=30 \%$, epidural $=50 \%$. Patients who merited management $(\mathrm{im}=10 \%, \mathrm{PCA}=5 \%$, epidural $=30 \%)$.

Pruritus: $\mathrm{im}=35 \%, \mathrm{PCA}=60 \%$, epidural $=85 \%$. Patients who merited management $(\mathrm{im}=5 \%, \mathrm{PCA}=5 \%$, epidural $=40 \%)$.

Sedation perceived by patients did not differ between groups, although it was higher for patients who received PCA and lower in the im group [11]. The prevalence of postoperative ileus related to the use of opioids in abdominal surgery (unspecified) is estimated between $10-30 \%$, nausea at $50 \%$, vomiting $20 \%$. $2.1 \%$ urinary retention related to spinal analgesia [12].

\section{Material and Methods}

The study is observational, descriptive, retrospective crosssectional, including all records of patients with protocolized analgesia with opioid use for the control of Acute Postoperative Pain carried out from March - September 2018, in the Specialty Hospital of the National Medical Center Century XXI. (Hospital de Especialidades Centro Medico Nacional Siglo XXI.) The inclusion criteria for the study were: postoperated patients electively / urgently with the classification of ASA I, II, III, who received analgesic protocol: intravenous, epidural, subarachnoid, with a minimum hospital stay of 24 hours, over 18 years. 
The elimination criteria were patients discharged before 24 hours, patients reoperated surgically, patients who have undergone assisted mechanical ventilation and who have been transferred to intensive care. Sample size calculation was convenient. The data collection was through a data collection sheet that included all the variables of interest of the study, which were emptied into a Microsoft Excel sheet for further exploratory analysis. Data are presented for quantitative variables in average and standard deviation, for qualitative variables in frequencies, percentages and from these simple tables were prepared. The prevalence was calculated by the number of cases that presented side effects among the total number of subjects studied multiplied by 100 . The statistical program SPSS version 22 was used. The work was submitted to the local Clinical Research and Ethics Research Committees of the "Specialty Hospital of the National Medical Center Century XXI" and approved with Registration Number R-2018-3601-144.

\section{Operational Description of the Study}

Once the study was approved by the research and ethics committees, the evaluation of the analgesic protocol records of the patients who received DAP management was performed. It covered the period of March - September 2018, the information was collected through the use of a data collection sheet designed specifically for this purpose, containing the variables of interest for the study. Demographic data were collected: age, sex, height, physical state of ASA, analgesic and opioid scheme used, route of administration, opioid dose, pathology. The filling of the data collection sheets was carried out by the same person, all the generated sheets were delivered to a researcher outside the data collection who was in charge of emptying their content in the previously coded Excel sheet and formatted to each study variable, the analysis of results was with the statistical program SPSS version 22 .

\section{Results}

The study included 320 patients (157 women, $163 \mathrm{men}$ ), the average age was 48 years, with a range of 19 - 57 years. The average weight in kilograms $(\mathrm{kg})$ was 73.07 , the average height of $1.65 \mathrm{~m}$ (Table 1). The physical condition of the patients that predominated was ASA III 42.2\% (135 patients). The overall observed prevalence of side effects related to the use of opioids in patients with protocolized analgesia was $43.75 \%$ (140 patients). The major side effect was nausea $19.4 \%$ (62 patients). No lethal side effects such as respiratory depression were found (Table 2). The most commonly used opioid for the management of DAP with the protocolized scheme was buprenorphine 46.3\% (148 patients), fentanyl $2.2 \%$ (7 patients) was the one with the least use (Table 3). The route of administration for the different opioids that was most used was intravenous $82 \%$, this was probably related to the physical condition $\geq$ III (Table 4 ). Table 5 shows the different routes of administration of the different opioids used for the control of DAP, as well as the observed side effects. $40.7 \%$
(57 patients) received intravenous morphine, and its side effects were: nausea $17.8 \%$ (25 patients), vomiting 16.4\% (23 patients).

Table 1: Demographic data.

\begin{tabular}{|c|c|}
\hline Variable & Result \\
\hline Sex M $/ \mathrm{F}(\%)$ & $157(49.1 \%) / 163(50.9 \%)$ \\
\hline Age in years & $48.4\left(\mathrm{DE}^{*} \pm 16.8\right)$ \\
\hline Weight in kg & $73\left(\mathrm{DE}^{*} \pm 14\right)$ \\
\hline Size cm & $1.65\left(\mathrm{DE}^{*} \pm 0.1\right)$ \\
\hline ASA I & $79(24.7 \%)$ \\
\hline ASA II & $100(31.3 \%)$ \\
\hline ASA III & $135(42.2 \%)$ \\
\hline ASA IV & $6(1.9 \%)$ \\
\hline Total & $320(100 \%)$ \\
\hline
\end{tabular}

F: Female, M: Male; DE*: Standard deviation, (\%) Percentage

ASA: classification of the physical state of the American Society of Anesthesiology.

Table 2: Prevalence of side effects in 320 patients who received.

\begin{tabular}{|c|c|}
\hline Side effects & Number (\%) \\
\hline Nausea & $62(19.37)$ \\
\hline Vomit & $47(14.68)$ \\
\hline Sedation & $15(4.68)$ \\
\hline Urinary retention & $2(0.62)$ \\
\hline Constipation & $2(0.62)$ \\
\hline Pruritus & $2(0.62)$ \\
\hline Headache & $10(3.12)$ \\
\hline Patients with side effects & $140(43.75)$ \\
\hline Without side effects & $180(56.25 \%)$ \\
\hline Total & $320(100 \%)$ \\
\hline
\end{tabular}

(\%): Percentage

Opioids by different routes of administration for the control of DAP.

Table 3: Main opioids used in protocolized analgesia.

\begin{tabular}{|c|c|}
\hline Type & Number (\%) \\
\hline Buprenorphine & $148(46.3)$ \\
\hline Morphine & $99(30.9)$ \\
\hline Tramadol & $66(20.6)$ \\
\hline Fentanyl & $7(2.2)$ \\
\hline Total & $320(100 \%)$ \\
\hline
\end{tabular}

(\%) Percentage

Table 4: Main routes of opioid administration in the management of DAP.

\begin{tabular}{|c|c|}
\hline Route of administration & Number (\%) \\
\hline Intravenous & $279(87.2)$ \\
\hline Epidural & $24(7.5)$ \\
\hline Subarachnoid & $17(3.5)$ \\
\hline Total & $320(100)$ \\
\hline
\end{tabular}

(\%): Percentage 
Table 5: Main side effects in 140 patients who received opioids through different routes of administration for the control of DAP.

\begin{tabular}{|c|c|c|c|c|c|c|}
\hline & \multicolumn{3}{|c|}{ Morphine } & \multirow{2}{*}{$\begin{array}{c}\text { Fentanyl } \\
\text { EPI }\end{array}$} & \multirow{2}{*}{$\begin{array}{c}\text { Tramadol } \\
\text { IV } \\
\end{array}$} & \multirow{2}{*}{$\begin{array}{c}\text { Buprenorphine } \\
\text { IV }\end{array}$} \\
\hline & IV & EPI & SA & & & \\
\hline & \multicolumn{6}{|c|}{ Number, (\%) } \\
\hline Nausea & $25(17.8)$ & $1(0.7)$ & $2(1.4)$ & $1(0.7)$ & $11(7.8)$ & $22(15.7)$ \\
\hline Vomit & $23(16.4)$ & $1(0.7)$ & $1(0.7)$ & $1(0.7)$ & $8(5.7)$ & $13(9.2)$ \\
\hline Sedation & $4(2.8)$ & 0 & 0 & 0 & $1(0.7)$ & $10(7.1)$ \\
\hline Urinary retention & 0 & 0 & $2(1.4)$ & 0 & 0 & 0 \\
\hline Constipation & 0 & 0 & $1(0.4)$ & 0 & 0 & $1(0.7)$ \\
\hline Headache & $4(2.8)$ & 0 & 0 & 0 & 0 & $6(4.2)$ \\
\hline Pruritus & $1(0.4)$ & 0 & $1(0.4)$ & 0 & 0 & 0 \\
\hline Total & $57(40.7)$ & $2(1.4)$ & $7(5)$ & $2(1.4)$ & $20(14.2)$ & $52(37.1)$ \\
\hline
\end{tabular}

Of 320 patients with postoperative opioid analgesia only 140 (43.75\%) side effects.

IV: Intravenous, EPI: Epidural, SA: Subaracnoidea, (\%): Percentage.

\section{Discussion}

The observed result of the 320 patients of the general prevalence was $43.7 \%$ (140 patients) related to the use of opioids for the control of DAP. Comparing the prevalence reported by Power I et al. [9], we are well above their estimate, which stood at $19 \%$ against $43.7 \%$ with a difference of $24.7 \%$; regarding the opioid with the highest side effects was morphine (29\%), this coincides with our results in the case of morphine was (intravenous $=40.7 \%$, epidural $=1.4 \%$, Subaracnoid $=5 \%$ ); where there are differences is that in their results respiratory depression was reported in $1 \%$ and hypotension in $5 \%$ while in our study no case was recorded. In contrast to the reported results of the incidence of side effects from the use of opioids with 3 analgesic techniques (im, PCA, epidural) by Dolin et al. [10] in the general average incidence of nausea, they reported $25.2 \%$ against $19.3 \%$. For the general average incidence of vomiting it was $20.2 \%$ against ours of $14.68 \%$. The method with which the major nausea was found was with PCA in our study was the continuous intravenous route with volumetric pump. The overall average incidence of mild sedation $(23.9 \%)$, excessive $(2.6 \%)=26.5 \%$ in our series was $4.68 \%$; The incidence of sedation for the epidural technique is the one that represents the least sedation, this coincides with our results. The overall average incidence of pruritus was $14.7 \%$ against ours of $0.62 \%$. Urinary retention was $23 \%$, for our report of $0.62 \%$. The technique that caused more urinary retention was the epidural which was observed in our study. The standardized criteria for the presence of side effects that were established for acute pain services in our results are below that cut-off point; $\mathrm{R}$ = recommendation; 0 = observed in our study: Nausea: $\mathrm{R}=25 \%$, $\mathrm{O}=19.37$; Vomiting: $\mathrm{R}=20 \%, \mathrm{O}=14.68 \%$; Slight Sedation $\mathrm{R}=$ $24 \%$, Excessive R $=2.6 \%$, Observed $=0.62 \%$; Pruritus $\mathrm{R}=14.7 \%$, $\mathrm{O}=0.62 \%$; Urinary retention $\mathrm{R}=23 \%, \mathrm{O}=0.62 \%$. The prevalence of postoperative ileus according to De Boer et al. [12] is between $10-30 \%$ versus the $0.62 \%$ we reported. In more recent studies, several risk factors that influence the presence of side effects have been studied. such as: nausea and vomiting; A very strong predictor is belonging to the female sex since this represents OR: 2.57; 95\% CI 2.32 - 2.84, the history of nausea-vomiting itself, dizziness OR: 2.09; $95 \%$ CI $1.90-2.29$, not being a smoker OR: 1.82; 95\% CI 1.68-1.92, Dizziness OR: 1.77; 95\% CI 1.55 - 2.04. While in anesthesia volatile anesthetics are the strongest factor with an OR: 1.82; 95\% CI $1.5-2.13$, followed by the anesthesia time OR: $1.46 \mathrm{~h} ; 95 \%$ CI $1.30-1.63 \mathrm{~h}$, the peri-operative use of opioids OR: 1.39; 95\% CI 1.20 - 1.60 [13]. The presence of adverse effects comparing the analgesic techniques of PCA with fentanyl + ketamine against epidural PCA with fentanyl in assisted video thoracic surgery, did not show differences between groups resulting in $23 \%$ (8 patients) for each group, these effects were mainly dizziness, nausea, vomiting, pruritus. In our study, these side effects were minor even though I included a majority of patients with ASA risk $\geq$ III [14].

Tramadol for DAP analgesia subcutaneously or intravenously in postoperative patients with inguinal plasty at a dose of $1.5 \mathrm{mg} /$ $\mathrm{kg} /$ weight was related to side effects such as nausea (12\%), and vomiting $(15 \%)$ in patients with ASA I -II, in our study the nausea and vomiting with tramadol was (7.8\%) and vomiting (5.7) being less than this report [15]. The presence of nausea in patients receiving opioids for the control of DAP can be $40 \%$ and vomiting $15-20 \%$, in some patients these symptoms can be considered worse than pain, these symptoms can trigger disturbances in the electrolyte balance, malnutrition, volume reduction, all this influences the quality of life and postoperative recovery [16]. Intrathecal morphine for the control of DAP [17] is related to an increase in pruritus (77\%), compared with intravenous administration with PCA (26\%), in our series intratecal administration with morphine represented few patients, this implies that it is a very little used route and perhaps the pruritus appeared $(0.4 \%)$; continuous epidural analgesia for DAP with morphine is associated with increased nausea - vomiting (OR: 1.91; 95\% CI 1.14 - 3.18; $\mathrm{p}=0.014$ ) compared with fentanyl [18], the percentage of patients of our patients who received epidural opioid (morphine or fentanyl) was $7.5 \%$, and 
the nausea, vomiting observed for each group was $(0.7 \%)$, these differences can probably be explained by low doses of opioid that are used. Multimodal analgesic protocols decrease the side effects related to the use of opioids, for example, in gastric sleeve surgery after the implementation of protocolized analgesia, the percentage of side effects was reduced from $33.8 \%$ to $8.8 \%$, with a significant reduction in the use of opioids in the postoperative period from $23.7 \mathrm{mg}$ to $0.7 \mathrm{mg}$ ( $\mathrm{p}<0.001$ ), these results favorably impact on the improvement of the peri-operative prescription since opioid consumption is reduced and therefore the epidemic of opioid abuse is reduced, and the treatment of DAP is better for patients with protocols. multimodal analgesics $[19,20]$, the management of the DAP in our hospital is in charge of the staff of the Acute Pain Medicine Service and the approach of the patients is with multimodal analgesic protocols that are individualized for each patient, this has allowed to reduce the doses of opioids and therefore the presence of adverse effects, the discharge of the DAP treatment is established by the acute pain service staff and as far as possible the use of opioids for pain control at the patient's home is avoided. A limitation of the study is that it is a retrospective study, which does not include the types of surgery which may interfere with the interpretation of the effect of opioid side effects in some types of surgery in particular. An advantage is that the results can be generalized since the type of patients presented in this sample are classified according to ASA $\geq$ III and this is because the hospital where the study was conducted is 3rd level of care that provides care for patients with high pathological complexity. This study will serve as a reference framework for specific studies by type of surgery and the side effects related to the use of opioids.

\section{Conclusion}

The side effects in patients who received protocolized analgesia that included opioids for the management of DAP in this study were lower than reported, this may be due to the anticipated management of side effects with the use of antiemetics, lower dose of opioids as recommended in the guides of multimodal analgesia. According to the recommended standards we are below the cutoff point of side effects.

\section{Interest conflict}

The participating authors declare to be free of any conflict of interest.

\section{References}

1. Montoya GA, Vaca C, Parra MF (2009) Detección de efectos secundarios asociados a la administración de tramadol y dipirona en un hospital de alta complejidad. Biomédica 29: 369-381.

2. (2008) Organización Mundial de la Salud. Medicamentos: seguridad y reacciones adversas.

3. Rodríguez-Betancourt JL, García-Vigil JL, Giral-Barnes C, HernándezSantillán D, Jasso-Gutiérrez L (2004) Farmacovigilancia I. El inicio. Rev Med IMSS 42(4): 327-329.
4. Walsh TD (1990) Prevention of opioid side effects. J Pain Symptom Manage 5(6): 362-367.

5. Pattinson KT, Governo RJ, MacIntosh BJ, Russell EC,Corfield DR, Tracey I, et al. (2009) Opioids depress cortical centersresponsible for the volitional control of respiration. J Neurosci 29(25): 8177-8186.

6. Ronald K (2006) Analgésicos opioides. En: Charles E, Zaid H. Secretos del tratamiento del dolor. 2a Edn 224-229.

7. Gándara A, Molero L, Vilches Y Dolor (2007) Analgésicos opioides. En: González B, Ordoñez A, Feliu J, Zamora P, Espinoza E. Tratado de Medicina Paliativa y Tratamiento de Soporte del Paciente con Cáncer. Madrid: Edn Médica Panamericana 333-350.

8. Rodríguez RF, Bravo LE, Castro F, Montoya O, Castillo JM, et al. (2007) Incidence of Weak Opioids Adverse Events in the Management of Cancer Pain: A Double-Blind Comparative Trial. Journal of Palliative Medicine 10(1): 56-60.

9. Power I (2005) Recent advances in postoperative pain therapy. Br J Anaesth 95(1): 43-51.

10. Dolin SJ, Cashman JN (2005) Tolerability of acude postoperatorive pain management: nausea, vomiting, sedation, pruritis, and urinary retention. Evidence from published data. Br J Anaesthesia 95(5): 584591.

11. Eisenach JC, Grice SC, Dewan DM (1988) Patient-controlled analgesia following caesarean section: a comparison with epidural and intramuscular narcotics. Anesthesiology 68(3): 444-448.

12. De Boer HD, Detriche O, Forget P (2017) Opioid related side effects: postoperative ileus, urinary retention, nausea, and vomiting and shivering. A review of the literature. Best Pract Res Clin Anaesthesiol 31(4): 494-504.

13. Apfel CC, Heidrich FM, Jukar-Rao S, Jalota L, Hornuss C, et al. (2012) Evidence-based analysis of risk factors for postoperative nausea and vomiting. Br J Anaesth 109(5): 742-753.

14. Tseng WCH, Lin WL, Lai HCH, Huang TW, Chen PH, et al. (2019) Fentanyl-based intravenosu patient controlled analgesia with low dose of ketamine is not inferior to thoracic epidural analgesia foracute postthoracotomy pain following video-asisted thoracic Surgery. Medicine 98(28): e16403.

15. dos Santos TO, Estrela TG, de Azevedo VL, de Oliveira OE, Oliveira G, Jr, et al. (2010) Intravenous and subcutaneous tramadol for inguinal herniorrhaphy: Comparative study. Rev Bras Anestesiol 60(5): 522527.

16. Mallick-Searle T, Fillman M (2017) The pathophysiology, incidence, impact, and treatment of opioid-induced nausea and vomiting. J Am Assoc Nurse Pract 29(11): 704-710.

17. Kim HC, Bae JY, Kim TK, Jeon Y, Min JJ, et al. (2016) Efficacy of intrathecal morphine for postoperative pain management following open nephrectomy. J Int Med Res 44(1): 42-53.

18. Youssef N, Orlov D, Alie T, Chong M, Cheng J, et al. (2014) What epidural opioid rsults in the best analgesia outcomes and fewest side effects after surgery? a meta-analysis of randomized controlled trials. Anesth Analg 119(4): 965-977.

19. Ng JJ, Leong WQ, Tan Cs, Poon KH, Lomanto D, So JBY (2017) A multimodal analgesic protocol reduces opioid-related adverse events and improves patient outcomes in laparoscopic sleeve gastrectomy. Obes Surg 27(12): 3075-3081.

20. (2019) Best practice in managing postoperative pain. The Lancet. 2019; 393(10180): 1478 


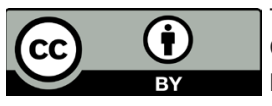

This work is licensed under Creative Commons Attribution 4.0 License

DOI: 10.19080/JAICM.2019.09.555778
Your next submission with Juniper Publishers will reach you the below assets

- Quality Editorial service

- Swift Peer Review

- Reprints availability

- E-prints Service

- Manuscript Podcast for convenient understanding

- Global attainment for your research

- Manuscript accessibility in different formats

( Pdf, E-pub, Full Text, Audio)

- Unceasing customer service

Track the below URL for one-step submission https://juniperpublishers.com/online-submission.php 